\title{
Cultural context and impact of alcohol use in the Sundarban Delta, West Bengal, India
}

\section{Citation}

Chowdhury, Arabinda N., Jayashree Ramakrishna, Ajoy K. Chakraborty, and Mitchell G. Weiss. 2006. "Cultural Context and Impact of Alcohol Use in the Sundarban Delta, West Bengal, India." In Social Science \& Medicine 63, no. 3: 722-731. doi:10.1016/j.socscimed.2006.02.006.

\section{Published Version}

doi:10.1016/j.socscimed.2006.02.006

\section{Permanent link}

http://nrs.harvard.edu/urn-3:HUL.InstRepos:35642346

\section{Terms of Use}

This article was downloaded from Harvard University's DASH repository, and is made available under the terms and conditions applicable to Other Posted Material, as set forth at http:// nrs.harvard.edu/urn-3:HUL.InstRepos:dash.current.terms-of-use\#LAA

\section{Share Your Story}

The Harvard community has made this article openly available.

Please share how this access benefits you. Submit a story.

\section{Accessibility}




\title{
Cultural Context and Impact of Alcohol Use in the Sundarban Delta, West Bengal, India
}

\author{
A.N. Chowdhury ${ }^{1}$, J. Ramakrishna ${ }^{2}$, A. K. Chakraborty ${ }^{3}$, \\ and Mitchell G. Weiss ${ }^{4}$
}

Submitted for publication:

Social Science and Medicine

23 December 2005

\section{Corresponding author:}

Mitchell Weiss, MD, PhD

Swiss Tropical Institute

Dept. Public Health \& Epidemiology

Socinstrasse 57,

CH4002 Basel

Switzerland

Tel: $\quad$ +41612848284

Fax: $\quad+41612717951$

Email: Mitchell-G.Weiss@unibas.ch

\footnotetext{
${ }^{1}$ Professor and Head, Department of Psychiatry, Institute of Postgraduate Medical Education and Research, Calcutta, India. anc@cal.vsnl.net.in

${ }^{2}$ Additional Professor and Head, Department of Health Education, National Institute of Mental Health \& Neuro Science, Bangalore, India. j_ramakrishna@vsnl.com

${ }^{3}$ Assistant Chief Medical Officer of Health, Diamond Harbor Subdivision, South 24 Paraganas, West Bengal, India. ajoychakraborty@vsnl.net

${ }^{4}$ Professor and Head, Department of Public Health and Epidemiology, Swiss Tropical Institute and University of Basel, Switzerland. Mitchell-G.Weiss@unibas.ch
} 


\section{Acknowledgements}

Support from the Swiss National Science Foundation, Grant \#32-51068.97, Cultural Research for Mental Health, is gratefully acknowledged. The dedication and diligence of the field research staff are appreciated. We are especially grateful to the community residents and leadership for their interest and cooperation in this study. Helpful suggestions of Sohini Banerjee based on a critical reading of an earlier draft and editorial assistance of Daryl Somma are appreciated. 


\section{Abstract}

Hazardous alcohol consumption is a worldwide problem with many locally distinctive features across cultures, but studies to guide policy in developing countries are notably lacking. This community study aimed to clarify local patterns of alcohol use in six villages of West Bengal, India. It considered the variety of local preparations, who consumed them, when, and where. It sought to determine how social changes in the region were influencing changing patterns of acceptable and problem use of alcohol. Ethnographic methods included participant observation and focus group discussions. Qualitative data analysis of field notes and transcripts included review of full texts and computer-assisted analysis of thematically coded segments with reference to a structured agenda for this ethnographic research. Drinking is an integral feature of the cultural landscape. Locally brewed rice beer (handia), palm wine (tadi), distilled country liquor (chullu), and so-called Indian-made foreign liquor (IMFL) are consumed in these villages. Each is identified with particular segments of society and settings in these communities. Reported effects of problem drinking included social disturbances, family discord, and domestic violence. Increasing problem alcohol use was attributed by villagers to social changes resulting from development, which were otherwise valued, such as improved transportation and communications. In a field dominated by Western and urban studies, this research has clarified features of alcohol availability, use, and acceptance in a neglected rural area of India. It has indicated the limitations of western clinical models of dependence and the importance of clarifying sociocultural conditions that define locally acceptable and problem use. 
Abstract word count: 250

Key Words: Alcohol, problem drinking, cultural drinking behaviour, substance abuse, community mental health, Sundarban Delta

Full text word count: 5,218 
Harmful use of alcohol is a recognised international health problem with serious health, social, and economic consequences. The World Health Assembly of 2005 has mandated study of the alcohol-related problems and the associated health burden, recognising for evidence-based strategies. Another recent WHO-supported initiative has emphsised the role of culture and gender and its relevance for controlling alcohol and substance abuse (WHO, 2004). Alcohol use is, in large measure, a culturally patterned feature of both secular and sacred life in most societies (Room et. al 2002). For developing effective public health programmes it is important to understand normative use, problem use, and the influence of social changes, such as urbanisation and globalisation. Normative drinking behaviour varies across cultures and within cultures.

Epidemiological public health studies of alcohol are mainly concerned with social and economic policies, and patterns of consumption and its impact (Mohan et al., 2001; Riley \& Marshall, 1999). Anthropological studies of alcohol consumption examine such behaviour in the context of broader sociocultural and ethnographical interests (Heath, 1987). Room and colleagues (2002) identify two main models of the cultural position of drinking: the holocultural model that characterise particular societies, and sociocultural patterns with reference to daily life and normative values for drinking practices (Room et al., 2002). Heath’s (2001) review of culture and substance abuse emphasises the importance of a cultural historical approach explaining local meanings, values, and norms associated with substance abuse to guide policy and clinical practice. Other researchers and policy planners also advocate ethnographic research and a mix of qualitative and quantitative methods for health policy-relevant studies (Heath, 2000, 1984; Marshall, 1990a; Marshall, 1990b; Gilbert, 199091).

India is a large country with diverse sociocultural and historical patterns of drinking. Most data on the topic is concerned with urban patterns of drinking, with less on rural areas where three-fourths of the population reside. Saxena's (1999) country study of alcohol in 
India reviews the history, types of alcohol, production and distribution, patterns of use, and psychiatric and general health problems. His account highlights the paucity of data on these topics and the need for further study to guide public health policy. In the course of developing a community mental health programme in the Sundarban region of West Bengal, India (Chowdhury, Chakraborty \& Weiss, 2001; Weiss, 2001), alcohol drinking was identified as an important issue for public health. This study aimed to examine community views of alcohol use. It focussed on beverages commonly consumed, drinking patterns, differences in consumption among different segments of society (e.g., tribals and non-tribals), changing patterns of use, and local distinctions between acceptable and problematic alcohol use.

\section{Study Area: Sagar and Gosaba Blocks of the Sundarban Region}

The Sundarban is an underserved and backward delta region, located at the confluence of the Hooghly River in the Bay of Bengal at the southernmost tip of the state of West Bengal, India (See Figure 1). Comprising 19 development blocks at the subdistrict level, the region is undergoing rapid social changes due to recent development of transportation, communications, and economic links with urban centres. The majority of the population remain dependent on agriculture, and traditional occupations such as fishing and, to a lesser extent, collection of honey and wood from the Sundarban reserve forest.

\section{\{Insert Figure 1 about here: Sundarban Delta, West Bengal, India\}}

The Sagar and Gosaba Island development blocks were selected for study because they have distinctive contrasting features. Sagar is relatively more developed. It has a ferry service that provides a good link with the mainland, and it is also the site of an annual Hindu 
festival that brings approximatley 400,000 people to the southern tip of the island every January. Paved roads and telecommunications on the island make contact with urban areas to the north easier. In contrast with the relatively more accessible Sagar Island block, Gosaba is closer to the tiger reserve, linked to the mainland only by country boats rather than a ferry. Communication links remain poor and development activities are minimal. The population of tribal people (adivasi) is greater in Gosaba. This adivasi population, comprising several distinct ethnic groups (Munda, Sardar, and Bhumij), are indigenous people of Bihar, who migrated to the Sundarban region to provide labour for deforestation and human settlement in the early 1900s. Limited availability of freshwater for drinking and irrigation is a serious problem in Gosaba. Three representative villages in each of the blocks were selected for study: Beguakhali, Rudranagar, and Phulbari in Sagar; and Jhaukhali, Arampur, and Dayapur in Gosaba.

\section{Research Methods}

Several ethnographic research methods were employed but data reported here was mainly gathered through in-depth interviews and group discussions. Four trained research assistants, with regular supervision by ANC and MGW, conducted interviews and discussions concerning the variety and distribution of alcohol preparations, community contexts of drinking, responses to problem drinking, adverse effects of alcohol use, and the various ways in which alcohol use and gender-related issues interact. Apart from specific issues on alcohol addressed in the guide, information on alcohol use emerged as an integral part of interviews concerning village life, including rituals, occupation, and other aspects of local village life.

Group interviews were conducted in both single sex and mixed groups; and some of these groups were organised according to age, occupation, religion, and marital status. An 
average of 9 to 10 group interviews per village and a total of 88 indepth interviews were conducted. Supervisors and field staff reviewed field notes and further details emerging from debriefing the field researchers were noted. Field staff translated field notes into English with supervisors’ assistance and entered into the computer using a word processing programme. The interviews and observations were analysed using a text analysis programme, initially TextBase Beta and subsequently MaxQDA (Kuckartz 2001). Coding was based on the study aims, literature, and field experience. This software facilitated coding with reference to the topics of the research agenda. The software provided easy access to thematically coded text segments from records selected according to location, sex, and other respondent or group interview characteristics. This software facilitated access to topics of interest at each of the six village sites for analysis.

\section{Results}

The following are findings from the villagers' accounts of available alcoholic beverages, their recreational and problem use, changing patterns of use, and the reasons for these changes. They suggested approaches for dealing with alcohol-related problems.

\section{Locally available alcoholic beverages}

Various alcoholic beverages were identified, some traditional and others of more recent origin.

\section{Rice beer (handia)}

Rice beer (handia), a traditional drink, contains 9-10\% alcohol. Indigenous people (Adivasis) regard it as both a food and an intoxicant. It is made from boiling parboiled rice and yeast (bakhar), derived from ground roots gathered in the forest. Fermentation takes 21/2 - 
3 days; the filtered drink resembles weak cream-coloured buttermilk. Most adivasi households produce handia for their own consumption and some sell their excess production to 'outsiders' at Rs. 2 per pot.

Adivasis, including men and women of all ages, drink handia as a staple beverage and typically consume it with a relish made of onions, chili and salt (chaat). It is believed that drinking handia from an earthen pot makes it more intoxicating (nesha). As an integral part of adivasi life, they also drink more of it on special occasions, such as weddings and at other cultural events. Handia is easily available in Gosaba, but in Sagar it is only available in the weekly and daily markets. Upper caste men and women, and salaried workers usually do not drink it, because they associate it use with lower caste groups. To protect their social status, those who do drink it usually do so privately. It is acceptable, however, for young boys to drink handia during festivals or at the annual Hindu pilgrimage festival on Sagar Island, the Ganga Sagar Mela.

\section{Palm wine (tadi)}

Palm wine, another traditional drink, is made from the fermented sap of the date palm (Phoenix sylvestris) and other palm trees. The sap is collected from slitting the bark of the tree, the original source of palm sugar, and when it ferments, it becomes palm wine. Palm wine is more readily available in Sagar throughout the year. It is shipped from Haldia, an industrial port to the north on the Hooghly River, where commercial processing adds yeast to increase the alcohol content. However, in Gosaba it is available only in the winter. Labourers, including van pullers (who pedal flatbed tricycles transporting people and goods) and collectors of tiger prawn seedlings in the rivers, drink this inexpensive tadi. A 750-ml bottle costs Rs. 20, and it is also sold in half and quarter bottles. 


\section{Country liquor (chullu)}

Country liquor (chullu, bangla) is made in a distillery (bhatikhana) from low-grade molasses (chitta gud), which is often used as cattle feed. Yeast is added to the molasses and fermented, and the brew is then distilled in a covered pot (bhatti); then it is diluted with water to reduce the alcohol concentration to $40-50 \%$. Chullu is sold in bottles, by the glass, or in polythene sachets, which cost Rs. 10 for $300 \mathrm{ml}$. Men whose livelihood requires heavy labour (such as pond diggers, van pullers, and tiger prawn seedling collectors) find it especially appealing. They explained that drinking chullu at the end of the day brings relief for body aches and pains. Some heavy drinkers take chullu regularly, but others, especially young men and boys, drink it only on special occasions like festivals.

Villagers can purchase chullu from local distilleries (bhatikhana) from some kiosks, roadside tea stalls, shops near bus stations, or at other places where people gather. Code names_ “pepsi” (associating it with the popular international beverage that is now available locally) or "50-gram muri (puffed rice, a traditional snack)" — are used to avoid mentioning the name "chullu." The packets are placed in paper bags so they look like packets of puffed rice. Retail distributors take the chullu on bicycles to various drinking places along the riverbanks or embankments, on trawlers, in hotels, picnic areas, and other spots where men hang out (adda).

\section{Indian-made foreign liquor, and foreign liquor}

Indian-made foreign liquor, known as IMFL, refers to whiskey or spirits made in India and labeled with fake foreign brand names. IMFL is socially regarded as a cut above chullu, available in clubs and favoured by people of higher status, such as businessmen, salaried people, military personnel, and government officials. A single licensed liquor store near Kochuberia, the ferry port on Sagar Island, sells IMFL. 
Imported foreign liquor is also available. Many ships unload cargo south of Sagar Island to lighten the ship for the journey through the silted channels to the Kolkata city port. Male day labourers from Sagar unload these ships, and they are often paid with a mix of cash and liquor. They may then resell the liquor, which has a ready local market among higher status men and in tourist hotels.

\section{Tonics and medicines}

In addition to liquor, people also consume various medicines and tonics with high alcohol content. The most popular are Amrita Sanjiboni Sura, Homeo 50 and Weak Ginger Tonic. Amrita Sanjiboni Sura (and its variants) is an Ayurvedic tonic and energiser costing Rs. 50-60 for a bottle of $200 \mathrm{ml}$. Businessmen, people in service and anyone who has ready cash can purchase it from Ayurvedic or medicine shops. It is often prescribed to women after childbirth. Homeo 50, a homeopathic energiser, and Amrita Sanjiboni Sura are also available in homeopathic medicine shops that are typically used by better-off villagers. Both rich and poor use Weak Ginger Tonic, an allopathic preparation that costs Rs. 30, and which is also available in medicine shops. Various types of local health care providers prescribe and promote these medicinal tonics; people may also choose to buy them on their own. A substantial number of persons were identified who were addicted to these tonics.

\section{Production and consumption of alcoholic beverages}

Ideas and associations about these various locally available alcoholic beverages, the particular settings, and ways in which they are consumed differed in Sagar and Gosaba. Gosaba has a large proportion of adivasis, and Sagar has a negligible tribal population. These adivasis brew rice beer for their own consumption and for sale. On Sagar, the better educated people who have more contact with the mainland typically prefer palm wine, foreign liquor, and the medicinal tonics. 
Rice beer is a favourite drink among lower caste men and labourers. They do not regard handia to be a hard drink, and so it does not share the negative connotations of drinking alcohol. A tea stall owner remarked that handia was also popular among traders, fishermen, and tiger prawn seedling collectors. A college-educated cultivator said that when men become frustrated, they occasionally drink handia, and this is not a social problem. A woman in Gosaba noted that housewives and young boys now also consume handia and chullu.

Chullu, country liquor, serves as currency in social rituals and as payment in transactions. For example, a foreman (mistry) who prepares the soil bed and plants betel leaf vines may receive two to three bottles of chullu as part of his remuneration. A traditional healer (gunin) of Phulbari, Sagar, skilled in removing the stinger of certain fish as well as in exorcising ghosts, prefers payment as a bottle of alcohol with a small amount of cash. Alcohol is also a regular feature of remuneration for some occupations. The pilot (majhi) and other labourors on commercial fishing trawlers receive monetary wages, supplemented in a final payment that includes bottles of chullu. After returning to port, the fishermen eat, drink, and also smoke ganja (cannabis), and the owner of the trawler is expected to cover these costs. Although fishermen do not drink or smoke ganja at sea, where such activity would be unacceptably dangerous, imbibing alcohol when they return is a perk of the job.

Alcohol is also woven into the fabric of social and religious life in various other ways. Marriages, funerals, and religious ceremonies (pujas) may all be occasions for consuming alcohol. During the days of puja when a deity is worshipped, drinking and unruly behaviour are forbidden and condemned. But at the conclusion of this worship, when the idols are taken in a procession for immersion in the river, it is acceptable for men and boys to drink and celebrate. At that point, their unruly behaviour is tolerated by their elders. A young man explained that it is impossible to engage in the vigorous dancing of the immersion procession without consuming alcohol. 
Furtive gambling and drinking are frequent, especially during weekly market days. Such behaviour is especially widespread and overt during the annual religious festivals (melas). The Ganga Sagar Mela, as noted above, is the largest of these festivals. All types of liquor, including foreign liquor, are available. Many holy men (sadhus) and pilgrims smoke ganja openly. We also found that heroin (pata) is also smoked less commonly.

A group of young men of Sagar observed that poor economy and the lack of job opportunities frustrate youngsters and make them depressed. Some men cope by drinking to forget such problems and family disputes. They also noted that two women "who have lost their chastity” took to drinking. Age-inappropriate drinking is also an increasing matter of concern.

\section{Drinking patterns at the two sites}

Drinking was more likely to be considered an increasing problem in Gosaba, and harmful effects were minimised in Sagar. A young male journalist in Gosaba estimated that $30 \%$ of the village men are drunkards. A 35-year-old male resident of a Sagar village reported that many people drink alcohol, but very few drink heavily or were addicted. Some residents in Sagar, however, were concerned about changing patterns of drinking. A middleaged woman who is active in village politics argued that in the past only the men working in the ports drank alcohol, but nowadays even the older children drink surreptitiously.

In Sagar drinking is not permitted at home or in the village, but may be okay outside. In Gosaba there is no such restriction. A woman in a focus group of sex workers in Sagar reported that most men drink outside their home, often while watching films in video parlours. This is acceptable. A few people, who drink excessively, also drink at home. Men returning from the Sabarh, the term for lengthy fishing expeditions of several weeks, typically celebrate their return by consuming alcohol and smoking ganja, but outside their own village. A woman in a Sagar Muslim women’s focus group suggested that alcohol 
consumption is very rare. Even if they do consume, she explained, they do not return home until the effect of alcohol has worn off. Consequently, a person who drinks outside may not be readily identified as a drinker within the community. In Sagar, however, where the transportation system is better developed, many bus drivers and conductors drink regularly, even while on duty.

Notwithstanding indications of problem drinking in Sagar, such problems are clearly greater in Gosaba. Furthermore, the remoteness of Gosaba, less stringent social sanctions generally, and greater cultural permissiveness of drinking among the tribal population of Gosaba all contribute to relatively more consumption of alcohol there.

\section{Changing patterns of drinking}

\section{Video parlours}

The recent proliferation of video parlours has had dramatic effects on the social environment. Preparations for these films require a generator to run the films and a supply of chullu and snacks for the viewers. Many of these parlours operate only at night, and show obscene films. These may be collages from several films, rather than full commercial releases. The environment invites group drinking. Elders bemoan the youngsters' lack of interest in better quality films, and their preference for commercial violence, sex, and drinking. An elderly priest in Sagar lamented, "Video is the twin brother of alcohol."

\section{Changing income}

The community associated both increasing and decreasing income with more drinking. A teacher in Sagar remarked that poor people, like van pullers and prawn seedling collectors, drink heavily, while the rich tend to keep away from alcohol. "If a poor man earns Rs. 10, he will spend Rs. 5 on drink.” Another educated man from the same village had a contradictory view. He said drinking has increased because of increasing wages and 
disposable income. Labourers may now earn as much as Rs. 60 per day, enabling them to easily spend Rs. 20 on alcohol. Tiger prawn seedling collection produced unprecedented income for teenagers, and they routinely spend a portion of that on drinking. An elderly man recalled that when people of his generation were young, they could only dream of drinking, but now the young men and even boys can do it. It has become common for fathers and sons to drink together, a practice unheard of in the past.

Drinking in higher income groups is likely to be less socially disruptive and in more private places, and in low-income groups drinking is likely to be more socially disruptive and in public places. Drunken behaviour is frowned upon in the community, and those with a better position in society are more sensitive to the loss of social prestige. This discourages public drunkenness among better-off people, and makes problem drinking more common among the poorer segments of society.

\section{Easier availability}

Although it was previously difficult to locate and purchase alcoholic beverages, with improved transportation by road and water, it has become easier for distributors to deliver alcohol to previously less accessible places. Easier access has increased drinking. Even at the remote Sundarban reserve forest tourist lodge, alcohol is easily available. In Phulbari, Sagar, five shops sell alcohol; and in Arampur, Gosaba, 17 families brew handia for sale. Packaging in polythene sachets in small quantities has made distribution and sale of alcohol effortless. Many informants noted that illegal liquor shops could not be closed easily, because some policeman and local politicians patronise them, the people who own these shops are wealthy and powerful 


\section{Social disturbances from drinking}

The community recognized adverse effects of drinking on the community and on drinkers' families. Men who drink disturb the peace, quarrel among themselves, and create difficulties for women in public places. The families of drinkers also suffer economic hardships; familial and other social relationships are disturbed, and physical and psychological violence often result from problem drinking. Such problems are especially devastating to families whose economic status is already precarious.

Drunken men disturb the social peace. In Phulbari, Sagar, we observed a group of them playing music throughout the night, dancing before an image of the goddess Shitala. Villagers objected and a fight broke out. The villagers beat up the unruly drinkers, when they became threatening. A village meeting had to be called the next morning, where the now sober men begged for forgiveness.

The problems of poor families are often most visible. Their intoxicated behaviour and disputes are likely to be more public, and their family quarrels are more likely to be heard throughout the neighbourhood. Because of the visibility of their problems, it may seem that more poor people drink and are troubled by problem drinking. Better-off segments of society have the means and interest in maintaining a façade of social respectability, and they can more easily keep such problems hidden from public view.

\section{Family relations}

Alcohol disrupts family life in various ways. It fuels marital conflict and conflicts with in-laws. Men who require more money to drink may demand higher dowries. The cost of drinking also affects domestic finances. Men keep more of their earnings for drinking and give less for household expenses. Drinking behaviour also makes them less willing to work, which leads to economic distress, family conflicts, and criminality. A chronic drunkard of Phulbari pawns the cooking vessels when he needs money to drink. When his wife protested, 
he beat her. A year earlier, in an inebriated state, he set fire to the thatch of his hut. Some women also feared health effects, that their husbands might die from drinking.

\section{Gender-related violence}

Women typically bear the brunt of antisocial behaviour from problem drinking. Women explained that alcohol turns men into beasts or makes them crazy. Men’s drinking restricts women's freedom of movement. Women complained that in some areas it is impossible for them to walk on the roads at night. Drunken men leave them no space to pass, make catcalls, and insult any women they encounter.

Male drinking also leads to domestic violence. Men drink and "torture” their wives mentally and physically. An Arampur woman noted that there were many drunkards in her village who beat their wives daily. According to a teacher, promiscuity, extramarital relations, and wife beating are the direct consequences of alcohol abuse.

Although many do, not all men who drink abuse their wives, and the nature of their abusive behaviours varies. Of the 11 men in one village who were identified as chronic drunkards, 5 beat their wives, and 3 beat them severely. In a women's focus group, one housewife observed that the number of drunkards in her village has been steadily increasing, and there are also more brawls.

The violence is often serious and sometimes fatal. A woman from Gosaba told us that a drunken man had bitten off a portion of his wife's ear. A woman from Sagar recounted the story of another woman who had been beaten badly and then hanged, but her death was passed off as suicide. Many suicides and attempts do in fact result from such domestic violence targetting women by drunken men.

An abused middle-aged wife summed up her desperation in the following statement: He is despicable and I wish that he would die! He has made my life miserable and even now he beats me up. He returns home drunk and creates a lot of 
commotion at night. Our children are grown up, and even though they are aware of what is happening, this doesn't stop him. I wish he would never return home. It hardly matters whether he lives or dies. He collects tiger prawn seedling, and he spends all his earnings on drinks. He doesn’t contribute anything towards running the household.

\section{Shame and blame of victimised women}

To maintain social standing, female victims of violence beaten by their alcoholic husbands are reluctant to speak about it. They prefer to keep the matter within their family. An Arampur woman explained:

Women bear all the beatings and do not tell anyone. If the neighbours intervene and try to protect a woman from her husband, or if they try to help solve the problems, then these women scold those neighbours for interfering. Women do not tell other people that their husbands are torturing them because they must continue to live with their husbands.

Women are also reluctant to seek outside help because they fear that they will have to face more difficulties. They fear being blamed or abandoned by their husbands. They know they must continue to live with their husbands in any event. A Sagar woman explained the situation:

This wife beating happens regularly. There is no use of the woman complaining to the village council (panchayat). After the litigation is over, the wife will be beaten even more. Some women who cannot bear it, but even if they report it to the police, it is of no use.

Efforts to bring the matter to the attention of women's groups (mahila samity) in Gosaba also proved to be ineffective. 


\section{Community responses to problem drinking}

Community actions to deal with problem drinking in Sagar have been more successful than in Gosaba. In Phulbari, Sagar, members of the panchayat appealed to the Excise Department to stop illegal sales, but that had little effect. Panchayat members, joined by other villagers, then destroyed a distillery and drums containing handia. In Beguakali, Sagar, the panchayat has imposed a fine for drinking in the village, which has been very effective. A man there opened a liquor shop and refused to close it when asked by the villagers to do so. The other villagers destroyed it. During the Ganga Sagar Mela villagers discovered that a couple was selling liquor to the pilgrims from their house in Beguakali, and as a result, the villagers beat the couple and drove the man from the village.

In Rudranagar village, Sagar, there are civic groups and social clubs in which businessmen are very active. Citizen's committees (nagarik samity) and the health committees (swasthya samity) may sanction beatings when problem drinkers and gamblers are caught. A male teacher and a panchayat member noted that these actions have reduced problem drinking. Those who continue to drink do so secretly and are careful to maintain self-control. As a result of these actions, the owner of a medicine shop explained that he now sees fewer people coming with injuries after drinking. Local political parties also supported destruction of the distillery and punishment of problem drinkers. Nevertheless, medicine shops continue to sell both ayurvedic and homeopathic tonics with high alcohol content, but these are considered medicinal, rather than recreational. They are less often associated with socially disturbing behaviour.

\section{Discussion}

Our findings indicate that although the Sundarban region is a remote area, a local network for the production and distribution of alcoholic beveridges is active and effective. 
The hierarchy of social classes in the community is associated with specific preferences. Perceived rates of consumption are increasing, and use of local tonics alleged to have health benefits has defined a new, socially acceptable pattern of consumption. Discussions of problem drinking were typically associated with adverse effects of social changes. For example, tiger prawn collection has had substantial social and economic effects. It has provided opportunities and financial resources to youth, reducing their dependence on parents and elders. Increased disposable income affords youth the ability to start drinking at an earlier age than young people in previous generations. Studies in other parts of India have also shown a similar disposition to spend on alcoholic drinks in Karnataka (Ganapathy \& Ghosh, 1994), Kerala (Gulati \& Gulati, 1999), and the Hindu Kush region of the Himalayas (Nagpal, 1999). Changing preferences and patterns of alcohol use in the Sundarbans are also relevant. The shift from locally produced and more nutritious beverages with low alcohol content, such as handia and palm wine, to distilled liquor contributes to the problems from drinking.

Our findings show that problem alcohol use is regarded mainly as a social problem, rather than a medical problem. Local concerns in the Sundarban region emphasise consequences of alcohol use that adversely affect the community, rather than the drinker's personal health. It is primarily the social fabric of community life that is at stake, because the drinker creates a nuisance in the streets or behaves violently. Consequently, clinical considerations are less relevant to community concerns. The comparative cultural question differs here from more typical cross-cultural critiques, which are concerned with applying diagnostic criteria inappropriately across cultures (Room et al., 1996). The focus on the clinical task of identifying individual cases for treatment differs from community concerns with deviance from community norms and changing community norms. These are the relevant issues for controlling problem drinking that concern the Sundarban communities, where the health service infrastructure and a community priority for clinical services to treat individuals with disorders of problem drinking are both lacking. 
Notwithstanding this lack of a clinical priority in the Sundarban communities, as we introduce a mental health component in health services, we also find it is difficult to apply the DSM and ICD criteria for disorders of problem drinking because they are rooted in different cultural values. For example, the criteria for dependence refer to "efforts to cut down," "interference with social, occupational or recreational activities," and "persistent use despite problems arising from use" (Schmidt \& Room, 1999). For binge drinking, such criteria fit poorly. Local priorities and contexts of problem alcohol use, as identified in this study, provide a more useful guide to effective community action that better fits local priorities. They include drinking within or outside the village, drinking publicly or privately, and associations with public disturbances (e.g., raucous behaviour outside video parlours) and domestic violence. Ultimately, as the infrastructure develops, these clinical and community perspectives must be reconciled.

A community action agenda in the region requires attention to the low age of initiation into drinking and opportunities for easy cash from collecting tiger prawns, which is more appealing than attending school (Chowdhury et al., 1999). Moreover, with a larger network of distribution linking urban and rural areas, it has become more difficult to restrict youngsters' access to liquor; it is sold more often now by outsiders supported by political and financial interests, rather than by local residents. The impact of exposure to values communicated through mass media, as in urban areas like Delhi (Varma, 2000), also promotes drinking in the region.

Efforts to control problem drinking varied across the six study villages. In Sagar where the community was more involved, efforts were more successful. The political commitment of the village councils (gram panchayat) at the local level has been a key factor. Because alcohol is not currently a professional medical concern in the local health centres, community action is needed to make this a priority that should involve the health system. In settings where traditional norms have become less influential, participatory methods to 
identify and address problem drinking are needed. Our study of these six Sundarban villages demonstrates the relevance of practical ethnographic research to guide both community actions and local health systems.

\section{References}

Chowdhury, A.N., Chakraborty, A.K., Weiss, M.G. (2001). Community mental health and concepts of mental illness in the Sundarban Delta of West Bengal, India. Anthropology and Medicine 8(1), 109-128.

Chowdhury, A.N., Chowdhury, S. and Chakraborty, A.K. (1999). Eco-stress, quality of life and mental health in the Sundarban Delta of India, International Journal of Medicine, 6, 59-63.

Ganapathy, S. and Ghosh, S. (1994). Concern and Conflict: A Report on Women's Work and Child Health and Development. Bangalore: Institute of Social Studies Trust.

Gilbert, M.J. (1990-91). The anthropologist as alcohologist: qualitative perspectives and methods in alcohol research, International Journal of Addiction, 25(2A), 127-47, and discussion 147-8.

Gulati, L. \& Gulati, M. (1999). Revisiting Kalyani, Former Agricultural Worker. Parts 1-2. Economic and Political Weekly, 34(52):3668-3676, 25-31 December.

Heath, D.B. (2001). Culture and substance abuse. Psychiatric Clinics of North America, 24(3), 479-496.

Heath, D.B. (2000). Drinking occasions: comparative perspectives on alcohol and culture. Philadelphia: Bruuner/Mazel Publications.

Heath, D.B. (1987). Anthropology and alcohol studies: current issues. Ann Rev Anthropology 16:99-120. 
Heath, D.B. (1984). Cross-cultural studies of alcohol use. Recent Developments in Alcohol, 2, 405-15.

Kuckartz, U. (2001). MAXqda: Max Qualitatative Data Analysis. Reference Manual. Berlin: VERBI Software.

Marshall, M. (1990a). Combining insights from epidemiological and ethnographic data to investigate substance use in Truk, Federated States of Micronesia. British Journal of Addiction, 85(11), 1457-68.

Marshall, M. (1990b). "Problem deflation" and the ethnographic record: interpretation and introspection in anthropological studies of alcohol. Journal of Substance Abuse, 2(3), 353-67.

Mohan, D., Chopra, A., Ray, R., \& Sethi, H. (2001). Alcohol consumption in India: a crosssectional study. In: Demers, A., Room, R., \& Bourgault, C., Eds. Survey of Drinking Patterns and Problems in Seven Developing Countries. Geneva: World Health Organizaion; pp 103-114.

Nagpal, S. (1999). Food Security in the Hindu Kush Himalayas. Economic and Political Weekly, 34(38):2717-2720, 18-24 September.

Riley, L., \& Marshall, M. (Eds). (1999). Alcohol and Public Health in 8 Developing Countries. Geneva: World Health Organization (http://whqlibdoc.who.int/hq/1999/WHO_HSC_SAB_99.9.pdf, accessed 22 July 2005).

Room, R., Jernigan, D., Carlini-Marlatt, B., Gureje, O., Makela, K., Marshall, M., MedinaMora, M. E., Monteiro, M., Parry, C., Partanen, J., Riley, L., \& Saxena, S. (2002). Alcohol and the Developing World: A Public Health Perspective. Helsinki: Finnish Foundation for Alcohol Studies in collaboration with World Health Organization.

Room, R., Janca, A., Bennett, L.A., Schmidt, L., \& Sartorius, N. (1996). WHO cross-cultural applicability research on diagnosis and assessment of substance use disorders: an 
overview of methods and selected results. Addiction, 91(2), 199-220 and 221-230 (comments).

Saxena, S. (1999). Country profile on alcohol in India. Ch 3. In: Riley, L., \& Marshall M. (Eds). Alcohol and Public Health in 8 Developing Countries. Geneva: World Health Organization; pp 38-60.

Schmidt, L., \& Room, R. (1999). Cross-cultural applicability in international classifications and research on alcohol dependence. Journal for Studies on Alcohol, 60(4), 448-462.

Varma, A. (2000). Impact of watching international television programs on adolescents in India: a research note. Journal of Comparative Family Studies, 31(1):, 117-126.

Weiss, M.G. (2001). Cultural epidemiology: an introduction and overview. Anthropology and Medicine 8(1), 5-29.

World Health Organization (WHO) (2004). Gender, alcohol and culture: the GENACIS international study. Http://www.who.int/substance_abuse/activities/genacis/en/; accessed 21 Aug 2005. 


\section{Figure and captions}

Figure 1. Sundarban Delta, West Bengal, India

\{SundarbanMap.jpg\} 